\title{
PENGARUH DIMENSI KOMITMEN PROFESIONAL TERHADAP PERILAKU ETIS AKUNTAN PENDIDIK DI PERGURUAN TINGGI NEGERI DAN PERGURUAN TINGGI SWASTA
}

\author{
Bunga Asih Pratiwi \\ Program Studi Akuntansi, Fakultas Ekonomi, Universitas Setia Budi \\ bungaasihpratiwi@gmail.com
}

\begin{abstract}
ABSTRAK
Penelitian ini bertujuan untuk memperoleh bukti empiris pengaruh dimensi komitmen profesional, yaitu affective professional commitment, continuance professional commitment, normative professional commitment, terhadap perilaku etis Akuntan Pendidik di Perguruan Tinggi Negeri dan Perguruan Tinggi Swasta. Sampel dalam penelitian ini diambil dengan menggunakan metode insidental sampling. Jumlah data sampel yang diolah sebanyak 101. Pengumpulan data menggunakan sumber data primer berupa kuesioner yang disusun dengan skala likerts lima poin. Teknik analisis data penelitian ini menggunakan teknik analisis regresi linier berganda. Hasil penelitian menunjukkan bahwa affective professional commitment tidak berpengaruh terhadap perilaku etis. Continuance professional commitment berpengaruh negatif terhadap perilaku etis. Selanjutnya normative professional commitment berpengaruh positif terhadap perilaku etis.

Kata Kunci : Affective Professional Commitment, Continuance Professional Commitment, Normative Professional Commitment, Perilaku Etis.
\end{abstract}

\section{ABSTRACT}

This study aims to obtain empirical evidence the affect of the dimensions of professional commitment, namely affective professional commitment, continuance professional commitment, normative professional commitment, to ethical behavior in Accountants Educators in State Universities and Private Universities. The sample in this study was taken using a insidental sampling method. The number of sample data processed was 101. Data collection using primary data sources in the form of a questionnaire was arranged with a five-point Likerts scale. The data analysis technique of this study used multiple linear regression analysis techniques. The results showed that affective professional commitment did not influence ethical behavior. Continuance professional commitment negatively affects ethical behavior. Furthermore normative professional commitment has a positive affect on ethical behavior.

Keywords : Affective Professional Commitment, Continuance Professional Commitment, Normative Professional Commitment, Ethical Behavior.

\section{PENDAHULUAN}

Seiring dengan adanya perkembangan zaman, biasanya diiringi dengan adanya perubahan perilaku manusia yang seringkali perilaku manusia tersebut dikaitkan dengan isu perilaku etis. Seorang profesional harus memiliki etika yang baik sebagai pola umum dan 
cara pandang dari sekumpulan aturan perilaku yang harus ditaati oleh pihak yang menjalankan profesi tersebut. Begitupun dengan akuntan pendidik yang perlu menerapkan perilaku yang beretika untuk merepresentasikan profesinya yang menjunjung tinggi perilaku moral dan memberikan contoh kepada mahasiswa didiknya.

Peran akuntan pendidik memiliki kontribusi besar untuk mengajar dan membagi ilmunya kepada mahasiswa agar mencetak sumber daya manusia yang profesional khususnya untuk mencetak para akuntan. Akuntan pendidik juga bertugas mendidik mahasiswa akuntansi untuk memiliki perilaku yang baik dan tidak melanggar kode etik profesi akuntan, untuk itu akuntan pendidik dituntut dapat memberikan panutan yang baik dalam berperilaku etis sesuai dengan kode etik profesi yang berlaku dan tidak menyimpang ataupun melanggar aturan yang telah ditetapkan. Permasalahan yang muncul dalam menjalankan tugas profesinya, masih banyak akuntan pendidik melakukan kesalahan yang melanggar kode etik profesi yang berlaku serta menyimpang dari perilaku etis, seperti; melakukan tindak plagiarisme, diskriminatif, indisipliner, melakukan pemaksaan hak terhadap mahasiswa, hingga tindakan pelecehan seksual (Meilisa dan Unti, 2010).

Seperti yang termuat dalam media massa beberapa sikap atau perilaku menyimpang akuntan pendidik diantaranya adalah sebagai berikut; dosen Fakultas Ekonomi Universitas Mataram (Unram) terlibat kasus tindak pidana asusila (ekonomi.kompas.com, 12 Maret 2009), dosen yang juga menjabat sebagai pembantu dekan IV Fakultas Ekonomi di Perguruan Tinggi Negeri Kota Kendari terlibat kasus ganja (ekonomi.kompas.com, 19 Januari 2011), seorang dosen dari Perguruan Tinggi Swasta (PTS) di Bandung melakukan tindakan plagiarisme dalam artikelnya (detiknews.com, 9 Februari 2010), serta kasus Anggito Abimanyu seorang Dosen Akuntansi di FEB UGM telah melakukan plagiarisme terhadap karya Hotbonar Sinaga (antaranews.com, 17 Februari 2014). Berbagai kasus pelanggaran etika tersebut seharusnya tidak terjadi apabila setiap profesi khususnya pada akuntan pendidik mengetahui, memahami, dan menerapkan perilaku etis secara memadai dan disiplin dalam melaksanakan profesinya serta memiliki rasa komitmen profesional yang tinggi.

Komitmen profesional sendiri sangat diperlukan dalam suatu organisasi sebagai bentuk dari karakter individu dan sikap loyalitas individu yang akan membentuk profesi seseorang. Komitmen profesional menurut Hall et al. (2005) menyebutkan adanya tiga dimensi dari komitmen profesional, yang terdiri dari Affective Professional Commitment (APC), untuk 
menilai sejauh mana individu ingin tinggal dalam profesi karena mereka ingin mencapai tujuan profesi, Continuance Professional Commitment (CPC), untuk menilai sejauh mana individu merasa mereka harus tetap dalam profesi karena akumulasi risiko dan biaya yang telah dikeluarkan dan Normative Professional Commitment (NPC), untuk menilai sejauh mana individu harus tetap menjalankan suatu profesi karena adanya rasa kewajiban serta tanggung jawab. Seseorang yang memiliki rasa komitmen profesional yang tinggi akan cenderung untuk berperilaku etis serta profesional dalam melaksanakan pekerjaannya. Selain itu, seorang profesional dalam hal ini adalah akuntan pendidik, apabila memiliki komitmen profesional yang tinggi mereka akan mendorong kemampuannya untuk terus belajar serta mengembangkan ilmunya yang berguna dan bermanfaat untuk lingkungannya.

Penelitian sebelumnya Meyer et al. (2002), dan Hall et al. (2005) menyatakan bahwa dimensi komitmen profesional Affective Professional Commitment (APC) menyatakan bahwa memiliki pengaruh positif terhadap perilaku etis. Namun, menurut penelitian Sukamto et al. (2014) dari hasil analisisnya diketahui bahwa Affective Professional Commitment (APC) tidak memiliki pengaruh terhadap perilaku etis untuk berpindah meninggalkan suatu organisasi. Menurut Hall et al. (2005) menunjukkan bahwa dimensi komitmen profesional Continuance Professional Commitment (CPC) memiliki efek positif terhadap perilaku etis, namun penelitian sebelumnya Islamy (2016), dan Sukamto et al. (2014) Continuance Professional Commitment (CPC) berpengaruh negatif terhadap perilaku etis seorang akuntan pendidik. Sedangkan menurut penelitian Meyer et al. (2002), dan Hall et al. (2005) sebelumnya diketahui bahwa dimensi komitmen profesional Normative Professional Commitment (NPC) memiliki hubungan yang positif terhadap perilaku etis, namun bertolak belakang dengan penelitian Sukamto et al. (2014) yang menyatakan bahwa Normative Professional Commitment (NPC) memiliki pengaruh negatif yang signifikan terhadap perilaku etis untuk berpindah meninggalkan suatu organisasi.

Penerapan perilaku para akuntan khususnya akuntan pendidik sudah seharusnya untuk menjunjung tinggi perilaku etis sesuai dengan kode etik akuntan yang sudah diatur dan ditetapkan oleh organisasi profesi, serta taat dan patuh terhadap aturan-aturan yang telah dibuat oleh organisasi tempat bekerja. Kedua penerapan peilaku tersebut tidak selalu sama dan seorang akuntan pendidik cenderung hanya mengutamakan salah satu sikap. Jika hal tersebut terjadi, akuntan pendidik akan dihadapkan pada perilaku yang dapat memicu 
terjadinya konflik, yakni loyalitas kepada profesi dan kepada organisasi. Hal ini menjadi menarik diteliti karena suatu konflik yang ditimbulkan dari perilaku etis berpotensi dapat menimbulkan ketidaknyamanan di dalam organisasi akibat dari tingkat komitmen profesional yang rendah.

\section{Tujuan Penelitian}

Adapun tujuan diadakannya penelitian ini adalah sebaga berikut :

a. Untuk menguji pengaruh Affective Professional Commitment (APC) terhadap Perilaku Etis Akuntan Pendidik di Perguruan Tinggi Negeri dan Perguruan Tinggi Swasta.

b. Untuk menguji pengaruh Continuance Professional Commitment (CPC) terhadap Perilaku Etis Akuntan Pendidik di Perguruan Tinggi Negeri dan Perguruan Tinggi Swasta.

c. Untuk menguji pengaruh Normative Professional Commitment (NPC) terhadap Perilaku Etis Akuntan Pendidik di Perguruan Tinggi Negeri dan Perguruan Tinggi Swasta.

\section{KAJIAN PUSTAKA DAN PENGEMBANGAN HIPOTESIS}

\section{Teori X dan Y}

Menurut Stephen dan Marry (2010) teori motivasi milik McGregor mengemukakan adanya dua pandangan yang nyata mengenai manusia, yang menyatakan bahwa pandangan pertama pada dasarnya adalah negatif yang disebut Teori $\mathrm{X}$, dan pandangan yang kedua pada dasarnya adalah positif yang disebut dengan Teori Y.

\section{Komitmen Profesional}

Menurut Trisnaningsih (2013) komitmen profesional dapat dikatakan sebagai tingkat loyalitas individu pada profesinya sesuai dengan tingkat pemahaman oleh individu tersebut. Dalam ilmu akuntansi, komitmen profesional dibagi menjadi tiga dimensi komponen komitmen profesional, yang terdiri dari Affective Professional Commitment (APC) yakni sejauh mana individu ingin tinggal dalam profesi karena adanya rasa emosional dan keyakinan untuk melakukan nilai-nilai yang ada di dalam organisasi, Continuance Professional Commitment (CPC), yaitu sejauh mana individu merasa mereka harus tetap dalam profesinya karena akumulasi investasi atau kurangnya sebanding dengan risiko dan 
biaya yang telah dikeluarkan, dan Normative Professional Commitment (NPC), yaitu sejauh mana individu merasa mereka harus tetap dalam profesinya karena rasa kewajiban (Hall et al., 2005).

\section{Affective Professional Commitment (APC)}

Affective Professional Commitment merupakan keterikatan emosional individu, kesamaan identitas dengan organisasi, dan keterlibatan dalam organisasi. Seseorang akan tetap berada di dalam organisasi karena memang memiliki keinginan untuk itu (Robbins dan Judge, 2008).

\section{Continuance Professional Commitment (CPC)}

Continuance Professional Commitment merupakan komitmen individu yang didasarkan pada pertimbangan tentang apa yang harus dikorbankan bila akan meninggalkan organisasi. Dalam hal ini individu memutuskan menetap pada suatu organisasi karena menganggap sebagai suatu pemenuhan kebutuhan (Robbins dan Judge, 2008).

\section{Normative Professional Commitment (NPC)}

Normative Professional Commitment merupakan perasaan wajib individu untuk tetap berada dalam organisasi karena keharusan untuk tetap bertahan dalam organisasi. Seseorang yang memiliki Normative Professional Commitment yang tinggi akan bertahan dalam organisasi karena mereka merasa seharusnya melakukan hal tersebut (Robbins dan Judge, 2008).

\section{Perilaku Etis}

Menurut Arifiyani (2012) perilaku etis merupakan suatu keyakinan mengenai suatu tindakan yang benar dan tindakan yang salah, atau tindakan yang baik dan tindakan yang buruk, yang dapat mempengaruhi hal lainnya. 


\section{KERANGKA PEMIKIRAN}

Adapun kerangka pemikiran penelitian ini digambarkan pada model sebagai berikut:

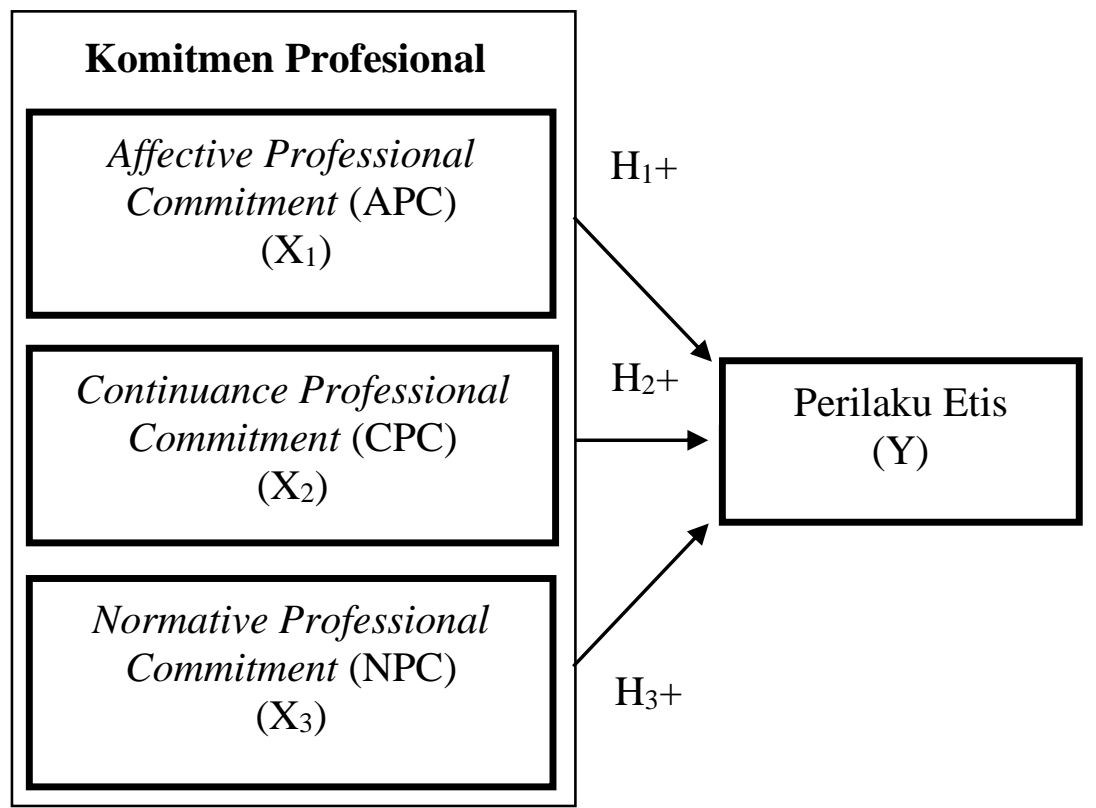

\section{Gambar 1}

\section{Model Penelitian}

\section{PENGEMBANGAN HIPOTESIS}

\section{Hubungan antara Affective Professional Commitment (APC) terhadap Perilaku Etis}

Semakin tinggi tingkat Affective Professional Commitment, maka perilaku etis Akuntan Pendidik juga tinggi. Sebaliknya, apabila semakin rendah tingkat Affective Professional Commitment, maka dapat menurunkan perilaku etis Akuntan Pendidik.

Penelitian Liu (2009) menemukan bahwa Affective Professional Commitment berhubungan positif terhadap perilaku etis. Demikian pula hasil penelitian Fitria (2003); serta Andriyanto dan Haerudin (2017) yang menyimpulkan bahwa Affective Professional Commitment berpengaruh positif terhadap perilaku etis. Berdasarkan uraian diatas dan hasil penelitian terdahulu, maka Hipotesis 1 (H1) dalam penelitian ini adalah :

H1: Terdapat Pengaruh Positif Affective Professional Commitment (APC) terhadap Perilaku Etis. 


\section{Hubungan antara Continuance Professional Commitment (CPC) terhadap Perilaku Etis}

Semakin tinggi tingkat Continuance Professional Commitment, maka perilaku etis Akuntan Pendidik juga tinggi. Sebaliknya, apabila semakin rendah tingkat Continuance Professional Commitment, maka dapat menurunkan perilaku etis Akuntan Pendidik.

Menurut hasil penelitian Fitria (2003); Andriyanto dan Haerudin (2017) yang menyimpulkan bahwa Continuance Professional Commitment memiliki pengaruh positif terhadap perilaku etis. Berdasarkan uraian diatas dan hasil penelitian terdahulu, maka Hipotesis $2(\mathrm{H} 2)$ dalam penelitian ini adalah :

H2: Terdapat Pengaruh Positif Continuance Professional Commitment (CPC) terhadap Perilaku Etis

\section{Hubungan antara Normative Professional Commitment (NPC) terhadap Perilaku Etis}

Seseorang yang memiliki Normative Professional Commitment yang tinggi akan bertahan dalam organisasi karena mereka merasa seharusnya melakukan hal tersebut. Sehingga dapat diambil kesimpulan bahwa semakin tinggi Normative Professional Commitment yang ada di dalam suatu organisasi dapat menaikkan tingkat perilaku etis seorang Akuntan Pendidik dalam organisasi untuk melakukan pekerjaan sesuai dengan profesinya, begitupun sebaliknya.

Hasil penelitian Fitria (2003); Andriyanto dan Haerudin (2017) menyimpulkan bahwa Normative Professional Commitment berpengaruh positif terhadap perilaku etis. Berdasarkan uraian diatas dan hasil penelitian terdahulu, maka Hipotesis $3(\mathrm{H} 3)$ dalam penelitian ini adalah:

H3: Terdapat Pengaruh Positif Normative Professional Commitment (NPC) terhadap Perilaku Etis.

\section{METODE PENELITIAN}

Penelitian ini menggunakan data primer. Desain penelitian yang dipakai yaitu menggunakan penelitian kausalitas . Populasi pada penelitian ini adalah Akuntan Pendidik yang ada di Perguruan Tinggi Negeri dan Perguruan Tinggi Swasta. Sampel yang digunakan 
dalam penelitian ini adalah insidental sampling. Menurut Sugiyono (2018) insidental sampling merupakan teknik penentuan sampel berdasarkan kebetulan, yaitu siapa saja yang secara tidak sengaja bertemu dengan peneliti dapat digunakan sebagai sampel, apabila orang yang tidak sengaja ditemui dipandang cocok dengan karakteristik sampel yang ditentukan sebagai sumber data penelitian.

Pengukuran Variabel :

a. Affective Professional Commitment (X1)

Variabel independen Affective Professional Commitment diukur dengan skala likert 5 poin, yaitu 1= STS (Sangat Tidak Setuju), 2= TS (Tidak Setuju), 3= KS (Kurang Setuju), 4= S (Setuju), dan 5= SS (Sangat Setuju) yang menggunakan jurnal Allen dan Meyer (1990) dengan indikator tertentu.

\section{b. Continuance Professional Commitment (X2)}

Variabel independen Continuance Professional Commitment diukur dengan skala likert 5 poin, yaitu 1= STS (Sangat Tidak Setuju), 2= TS (Tidak Setuju), 3= KS (Kurang Setuju), 4= S (Setuju), dan 5= SS (Sangat Setuju) yang menggunakan jurnal Allen dan Meyer (1990) dengan indikator tertentu.

\section{c. Normative Professional Commitment (X3)}

Variabel independen Normative Professional Commitment diukur dengan skala likert 5 poin, yaitu 1= STS (Sangat Tidak Setuju), 2= TS (Tidak Setuju), 3= KS (Kurang Setuju), 4= S (Setuju), dan 5= SS (Sangat Setuju) yang menggunakan jurnal Allen dan Meyer (1990) dengan indikator tertentu.

d. Perilaku Etis

Variabel dependen Perilaku Etis diukur dengan skala likert 5 poin, yaitu $1=$ STS (Sangat Tidak Setuju), 2= TS (Tidak Setuju), 3= KS (Kurang Setuju), 4= S (Setuju), dan 5= SS (Sangat Setuju) yang menggunakan jurnal Pamela (2014) dengan indikator tertentu.

\section{Uji Hipotesis}

$Y=\alpha+\beta 1 X 1-\beta 2 X 2+\beta 3 X 3+e$

Keterangan :

$\mathrm{Y}$

$\alpha$
= Variabel dependen (Perilaku Etis)

$=$ Konstanta 
$\beta 1, \beta 2, \beta 3=$ Koefisien regresi variabel independen

$X_{1}$

= Variabel independen 1 (Affective Professional Commitment)

$X 2$

$=$ Variabel independen 2 (Continuance Professional Commitment) $X 3=$

Variabel independen 3 (Normative Professional Commitment)

$e$

$=$ Standard error

\section{HASIL DAN PEMBAHASAN}

Berdasarkan hasil output SPSS 23, menunjukkan bahwa:

Sumber: Data Primer yang diolah, 2020.

Berdasarkan hasil perhitungan regresi yang telah diperoleh, maka dapat dibentuk persamaan model regresi sebagai berikut:

$$
Y=3,283+0,155 X 1-0,277 X 2+0,362 X 3+e
$$

Dari persamaan model regresi diatas dapat dijelaskan bahwa:

1. Konstanta $(\alpha)$

Nilai dari konstanta sebesar 3,283 mengidentifikasi bahwa jika variabel independen yaitu Affective Professional Commitment, Continuance Professional Commitment, dan Normative Professional Commitment dianggap konstan, maka variabel dependen Perilaku Etis nilainya sebesar 3,283.

2. Koefisien $\beta 1$ Variabel Affective Professional Commitment (APC)

Nilai koefisien Affective Professional Commitment positif sebesar 0,155. Hal ini menunjukkan bahwa setiap terjadi kenaikan $1 \%$ pada Affective Professional Commitment akan mengakibatkan naiknya tingkat Perilaku Etis sebesar 0,155. Namun nilai signifikansi pada penelitian ini sebesar $0,155(>0,05)$ yang mengindikasikan bahwa variabel Affective Professional Commitment tidak berpengaruh secara signifikan terhadap Perilaku Etis. Sehingga naik dan turunnya Affective Professional Commitment tidak akan mempengaruhi Perilaku Etis.

3. Koefisien $\beta 2$ Variabel Continuance Professional Commitment (CPC)

Nilai koefisien Continuance Professional Commitment bernilai negatif sebesar -0,277. Hal ini menunjukkan bahwa setiap terjadi perubahan kenaikan $1 \%$ pada Continuance 
Professional Commitment maka akan mengakibatkan turunnya tingkat Perilaku Etis sebesar 0,277 .

\section{Koefisien $\beta 3$ Variabel Normative Professional Commitment (NPC)}

Hasil nilai dari koefisien Normative Professional Commitment sebesar 0,362. Tanda positif pada hasil koefisien variabel ini menunjukkan bahwa setiap terjadi perubahan kenaikan Normative Professional Commitment sebesar 1\% akan mengakibatkan naiknya tingkat Perilaku Etis sebesar 0,362.

\section{KESIMPULAN}

Berdasarkan hasil penelitian dan hasil pengujian hipotesis maka dapat diambil kesimpulan sebagai berikut:

1. Berdasarkan hasil pengujian hipotesis pertama (H1) dinyatakan ditolak.

2. Berdasarkan hasil pengujian hipotesis kedua (H2) dinyatakan ditolak.

3. Berdasarkan hasil pengujian hipotesis ketiga $(\mathrm{H} 3)$ dinyatakan diterima..

\section{KETERBATASAN PENELITIAN}

Penelitian ini memiliki sejumlah keterbatasan, antara lain; (1) Tingkat keterlibatan respons rate Akuntan Pendidik di Perguruan Tinggi Negeri dan Perguruan Tinggi Swasta untuk menjadi responden dalam penelitian ini relatif sangat sedikit. (2) Metode penyebaran kuesioner dalam penelitian ini beberapa dilakukan secara langsung dengan mengirim berkas kuesioner penelitian dalam bentuk hard copy ke beberapa Perguruan Tinggi yang dapat dijangkau oleh peneliti, yaitu dengan menitipkan beberapa kuesioner kepada Kepala Tata Usaha terkait dikarenakan beberapa Akuntan Pendidik sering tidak ada di dalam ruangannya.

\section{SARAN}

Berdasarkan hasil penelitian serta hal-hal yang terkait dengan keterbatasan penelitian ini, maka dapat diberikan saran-saran sebagai berikut; (1) Penelitian selanjutnya disarankan untuk dapat lebih menjangkau semua sampel sesuai dengan yang diharapkan. (2) Hasil penelitian ini diharapkan mampu menjadi kajian referensi bagi penelitian selanjutnya dan diharapkan dapat mengembangkan penelitian ini, seperti menambah jumlah sampel penelitian, 
menggunakan obyek penelitian yang berbeda atau menambah variabel independen lainnya agar hasil penelitian selanjutnya bisa semakin lebih baik.

\section{DAFTAR PUSTAKA}

Allen, N.J. dan Meyer, J.P. 1990. The Measurement and Antecedents of Affective, Continuance and Normative Commitment. Journal of Occupational Psychology, Volume 63, Nomor 1, Halaman 1-18.

Andriyanto, I., dan Haerudin. 2017. Peran Komitmen Organisasi Sebagai Mediator Pengaruh Etika Kerja Islam Terhadap Sikap Pada Perubahan. Jurnal Keuangan dan Perbankan Syariah, Volume 1, Halaman 17-29.

Fitria, A. 2003. Pengaruh Etika Kerja Islam Terhadap Sikap Akuntan Dalam Perubahan Organisasi Dengan Komitmen Organisasi Sebagai Variabel Intervening. Jurnal Maksi, Volume 3.

Gusnita, C. 2010. Prof Banyu Perwita Enggan Komentar Soal Plagiarisme. (https://news.detik.com/berita/d-1295857/prof-banyu-perwita-enggankomentar-soal-plagiarisme/komentar, diakses 3 September 2019).

Hakim, L. 2014. Anggito Abimanyu Mundur dari UGM Setelah Dituduh Plagiat. https://www.antaranews.com/berita/419472/anggito-abimanyu-mundurdari-ugm-setelah-dituduh-plagiat, diakses 3 September 2019.

Hall, M., David S., dan Langfield. 2005. Accountant's Commitment to Their Profession: Multiple Dimensions of Professional Commitment and Opportuinities for Future Research. Behavioral Research in Accounting, Volume 17, Halaman 89-109.

Islamy, F. 2016. Pengaruh Komitmen Afektif, Komitmen Normatif Dan Komitmen Berkelanjutan Terhadap Turnover Intention pada Dosen Tetap STIE Inaba Bandung. Jurnal Indonesia Membangun, Volume 15, Nomor 2.

Joewono, B. 2011. Dosen dan Rekanan Terlibat Kasus Ganja. (https://ekonomi.kompas.com/read/2011/01/19/19352058/ Regional Indone sia\%20Timur, diakses 3 September 2019).

Liu, Y. 2009. Perceived Organizational Support and Expatriate Organizational Citizenship Behavior: The Mediating Role of Affective Commitment Towards The Parent Company. Personnel Review, Volume 38, Nomor 3, Halaman 307-319.

Meilisa, F., dan Unti, L. 2010. Persepsi Mahasiswa Akuntansi Terhadap Etika Akuntan Pendidik di Jurusan Akuntansi Fakultas Ekonomi Universitas Brawijaya. Jurnal Akuntansi Multiparadigma, Volume 1, Nomor 2.

Meyer, J. P., Stanley, D. J., Herscovitch, L., dan Topolnytsky, L., (2002). Affective, Continuance, and Normative Commitment to the Organization: A Meta-analysis of Antecedents, Correlates, and Consequences. Journal of Vocational Behavior, Volume 61, Nomor 1, Halaman 20-52.

Ono. 2009. Penahanan Dosen Cabul Disaksikan Istrinya. (https://ekonomi.kompas.com/read/2009/03/12/1445233/penahanan.dosen.ca bul.disaksikan.istrinya, diakses 3 September 2019).

Robbins dan Judge. 2008. Perilaku Organisasi. Jakarta: Salemba Empat. 
Stephen, R., dan Marry. 2010. Manajemen Edisi Kesepuluh. Jakarta: penerbit Airlangga.

Sugiyono. 2018. Metode Penelitian Kuantitatif, Kualitatif, dan R\&D. Bandung : Alfabeta.

Sukamto, H., Junarto, Y., Kaihatu, T., dan Kartika, E. 2014. Analisa Pengaruh Komitmen Afektif, Komitmen Normatif Dan Komitmen Berkelanjutan Terhadap Perilaku Etis di Dragon Star Surabaya. Jurnal Hospitality dan Manajemen Jasa, Volume 21, Nomor 19. Trisnaningsih, S. 2013. Motivation and Commitment as Contingencies to Improve Graduate Competency. International Journal of Academic Research, Volume 5. 